\title{
Dietary Diversity in Agricultural and Coastal Area as Potential Source for the Prevention of Child Stunting in Sidoarjo District
}

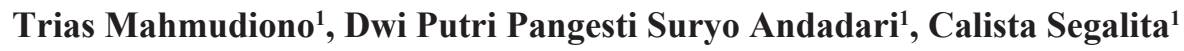 \\ ${ }^{1}$ Departement of Nutrition, Faculty of Public Health, Universitas Airlangga, Jl. Mulyorejo Kampus C, Indonesia
}

\begin{abstract}
Stunting is one of public health nutrition problem in Indonesia that will likely reduce the potential human resouces capacity in the near future. However, Indonesia could have prevented the problem since it has the potential food sources from the agricultural and coastal region. This study aimed to analyze the relationship between dietary diversity in the agricultural and coastal area with the prevalence of child stunting.

The design of the study was cross sectional involving 55 under five years old children and their mother. Dietary diversity was measured using the Individual Dietary Diversity Score (IDDS) and stunting was determined using height-for age index using the WHO 2005 standard. Statistical analysis used to test the hypothesis was logistic regression. The results showed that the prevalence of child stunting was $28 \%$. Food groups consumed in the agricultural as well as coastal area were dominated by starchy food, meat, fish and egg. There was significant correlation between child stunting and dietary diversity in agricultural and coastal area in Sidoarjo District ( $\mathrm{p}$-value $=0,019 ; \mathrm{OR}=5,49 ; 95 \% \mathrm{CI}=1,32-22,93$ ). Compare to children living in a houshold with good dietary diversity, those who live in a poor dietary diversity household have 5 times risk of being stunted. In conclusion, the significant correlation between good dietary diversity in the agricultural and coastal area of Sidoarjo District and child stunting indicated potential diet to reduce stunting. The majority of the diet in the study involved consumption of starchy food, fish and egg.
\end{abstract}

Keywords: dietary diversity, stunting, agriculture, coastal area

\section{INTRODUCTION}

Children need sufficient food to support the process of growth and development both physically and motoric ${ }^{(1)}$. Growth and development during childhood will be optimal with the right amount and good quality food $^{(2)}$. Nutrients deficiency in children causing decreased physical growth and motor development ${ }^{(1)}$. According to the Indonesian Ministry of Health, malnutrition in infant causes a higher risk of chronic illness when they grow ${ }^{(3)}$.

\section{Corresponding Author:}

Trias Mahmudiono

Departement of Nutrition, Faculty of Public Health, Universitas Airlangga, Jl. Mulyorejo Kampus C, Surabaya 60115, Indonesia

Phone: +62 315964808

Email: trias-m@fkm.unair.ac.id
Problems of malnutrition and excessive nutrients can be prevented by socializing balanced-nutrition messages. Consuming a variety of food consisting of staple food, side dishes, vegetables, and fruits and with considering the amount and type according to the needs, is the principle of balanced nutrition ${ }^{(3)}$. Introducing and providing a variety of food items for children can complement the nutrients needed because each food contains different nutrients ${ }^{(2)}$.

Based on the Ministry of Agriculture in 2016, adequate food fulfillment can be reflected from the availability of food. Indonesia as an agrarian and maritime country has the potential to provide food sources. The fulfillment of food still rely on agricultural resources, yet empower other resources such as fisheries ${ }^{(4)}$. Rice consumption in 2015 is $98.39 \mathrm{~kg} / \mathrm{cap} /$ year and this figure shows an increase of $1.22 \%$ from $2014^{(5)}$.

Research on the diversity of food as measured by Dietary Diversity Score (DDS) in Ghana shows that the 